\title{
Effect of Nickel Addition on the Corrosion Resistance of Steel in a Subtropical Seashore Environment
}

\author{
Hina SATO, ${ }^{1) *}$ Minoru ITO $^{11}$ Kazuyuki KASHIMA, ${ }^{1)}$ Michio KANEKO, ${ }^{1)}$ Makoto NAGASAWA ${ }^{2)}$ and Takashi DOI ${ }^{3)}$ \\ 1) Steel Research Lab., Nippon Steel Corp., Amagasaki, 660-0891 Japan. \\ 2) Plate Technology Div., Nippon Steel Corp., Tokyo, 100-8071 Japan. \\ 3) Advanced Technology Research Lab., Nippon Steel Corp., Amagasaki, 660-0891 Japan.
}

(Received on November 15, 2019; accepted on February 25, 2020; J-STAGE Advance published date: May 2, 2020)

\begin{abstract}
This study investigated the effects of $\mathrm{Ni}$ addition on the corrosion resistance of steel in subtropical seashore environments. Carbon steel and 3, 5, and 7\% Ni steels were exposed in such an environment for a year. Addition of $\mathrm{Ni}$ depressed the corrosion rate of steels and number of cracks in the rust layer. Quantitative and three-dimensional measurement of the cracks with a wide range of widths and volumes in the rust layer was carried out for the exposed steel specimens using the mercury intrusion method. The total crack volume in the rust layers on $5 \% \mathrm{Ni}$ steel was $60 \%$ lower than that for the carbon steel. It is considered that rust layers with less crack volume suppressed $\mathrm{Cl}^{-}$migration through the rust layer. The $\mathrm{Cl}$ concentration near the metal interface was relatively lower in the 5\% Ni steel by EPMA analysis. And the rust layer on $5 \% \mathrm{Ni}$ steel also showed a higher permeation resistance than that formed on carbon steel. Considering the formation of rust layers with less volume crack on Ni-added steel based on Morcillo's model, it is concluded that the Ni addition promoted the formation of a-FeOOH and suppressed the reduction of $\gamma$ - and $\beta$ - $\mathrm{FeOOH}$, thus resulting in a more intact rust layer.
\end{abstract}

KEY WORDS: atmospheric corrosion; subtropical sea shore; Ni added steel; rust; crack; mercury intrusion method; anodic dissolution.

\section{Introduction}

Weathering steel (WS) is a low-alloy steel mainly containing $\mathrm{Cu}, \mathrm{Cr}$, and $\mathrm{Ni}$ with improved atmospheric corrosion resistance. Enhanced corrosion resistance of WS is attributable to the formation of fine-grained and highly adherent protective rust. $^{1-3)}$ However, steel structures in Japan, an island country, are subjected to airborne salt and high humidity that interfere with the formation of this protective rust. Hence, Japanese steel manufacturers have collaborated to conduct exposure tests to clarify geographical regions suitable for the use of WS. In Japan, the maximum acceptable deposition rate of airborne salt on unpainted WS is less than $0.05 \mathrm{mg} / \mathrm{dm}^{2} \cdot$ day (hereinafter abbreviated to mdd) according to three Japan institutions (the Ministry of Construction's public Works Research Institute, Kozai Club and the Japanese Steel Bridge Construction Association). ${ }^{4)}$ However, there is a strong demand for WS with superior corrosion resistance in environments with higher airborne salt concentrations.

An advanced type of WS, "3\%Ni advanced weathering steel", was newly developed in Japan as a corrosionresistant steel. It is based on the discovery that Ni addition can ensure the formation of protective rust in high-salinity environments. ${ }^{5-8)}$ Exposure tests were conducted for steels

\footnotetext{
* Corresponding author: E-mail: satoh.qm7.hina@jp.nipponsteel.com DOI: https://doi.org/10.2355/isijinternational.ISIJINT-2019-658
}

added with various amounts of $\mathrm{Ni}$ in distinct regions of Japan, ${ }^{9)}$ in order to systematically examine the corrosion inhibition effects under different amounts of chloride. Based on the test results, software was developed to predict the applicable area of " $3 \% \mathrm{Ni}$ advanced weathering steel" by determining the possibility of forming a protective rust. ${ }^{10)}$

The " $3 \% \mathrm{Ni}$ advanced weathering steel" did not form protective rust in the subtropical seashore area. Nevertheless, an exposure test showed that the corrosion loss of Ni-containing steels was much smaller than that of carbon steel in that area. ${ }^{11)}$ Corrosion characteristic of carbon steel in subtropical seashore areas is the formation of exfoliated rust layer on the surface. Morcillo et al. reported the mechanism of rust exfoliation on carbon steel in a high-salinity area. ${ }^{12)}$ By exposing samples in the marine atmosphere of Cabo Vilano (Spain) and analyzing the rust layer in detail, they concluded that $\gamma$ - and $\beta$-FeOOH were reduced to $\mathrm{Fe}_{3} \mathrm{O}_{4}$ accompanied by a volume change, and this volume change caused crack generation and rust exfoliation. Their findings suggest that the better corrosion resistance of Ni-containing steels in the subtropical seashore area could be due to suppressed crack formation caused by the rust reduction reaction.

In this study, we conducted exposure tests of carbon steel and Ni-containing steels ( 3 to $7 \% \mathrm{Ni}$ ) in a subtropical seashore area. Rust layers formed on the steels were characterized by various techniques. In particular, the width and volume of cracks in the rust layers were quantitatively mea- 
sured using the mercury intrusion method. The enhanced corrosion resistance after adding $\mathrm{Ni}$ was discussed in terms of depressed crack formation in the surface rust layers, based on the report by Morcillo et al.

\section{Experimental}

\subsection{Materials}

Table 1 shows the chemical composition (mass\%) of the exposure test specimens. Carbon steel specimens $(7 \mathrm{~mm}$ thick) were used as the reference material. Twenty-kilogram ingots containing 3-7 mass $\% \mathrm{Ni}$ were produced from a vacuum induction furnace, heated at $1200^{\circ} \mathrm{C}$, and hot rolled to $7 \mathrm{~mm}$. The rolled pieces were then kept at $950^{\circ} \mathrm{C}$ for 15 min and cooled in air. Specimens of $60 \mathrm{~mm} \times 100 \mathrm{~mm} \times 5$ $\mathrm{mm}$ were mechanically cut from the $7-\mathrm{mm}^{\mathrm{t}}$ steel plates and shot blasted on both sides to Sa2 1/2 (ISO8501-1).

\subsection{Exposure Test}

The exposure test was conducted from July 2015 to July 2016 at Miyakojima Seashore Exposure Site (north latitude $24^{\circ} 42$, east longitude $125^{\circ} 18^{\prime}$ ) of the Japan Weathering Test Center. The specimens were exposed on a south-facing rack at an angle of $30^{\circ}$ from the horizontal. The deposition rate of airborne salt at this site was approximately 1.1-1.2 mdd (equivalent to corrosivity category CX of ISO 922392). According to the Japan Meteorological Agency (http:// www.jma.go.jp/jma/index.html), the average temperature at Miyakojima City was $24.3^{\circ} \mathrm{C}$, the average relative humidity was $78.3 \%$, and the average annual precipitation was 2193 $\mathrm{mm}$ in 2015-2017. All the analyses and measurements described below were conducted on the skyward-facing, exposed surface of the specimens.

\subsection{Analysis of Specimens}

The rust layers on the carbon steel and Ni-containing steels were removed mechanically and chemically. The corrosion loss of the steel was determined by the mass change. The cross-sections of the rust layer were investigated by polarizing microscopy. The elemental distribution in the rust layer was analyzed by an electron probe micro-analyzer (EPMA; JXA-8900, JEOL Ltd., Japan).

Quantitative identification of chemical species in the rust was conducted by X-ray diffraction (XRD), using the calibration curves prepared from the diffraction peak intensity ratios of standard materials $(\alpha-\mathrm{FeOOH}, \beta-\mathrm{FeOOH}$, $\gamma$-FeOOH, $\mathrm{Fe}_{3} \mathrm{O}_{4}$, and $\left.\mathrm{ZnO}\right) .{ }^{13)}$ A rust sample of $200 \mathrm{mg}$ was taken from the metal interface, ground in a mortar, and mixed with $50 \mathrm{mg} \mathrm{ZnO}$ as standard material. The XRD patterns were measured with a Rigaku RINT-2500 X-ray diffractometer, using a Co target at a scan speed of $2 \%$ min

Table 1. Chemical composition (mass\%) of tested samples.

\begin{tabular}{ccccccccc}
\hline & $\mathrm{C}$ & $\mathrm{Si}$ & $\mathrm{Mn}$ & $\mathrm{P}$ & $\mathrm{S}$ & $\mathrm{Ni}$ & $\mathrm{Cu}$ & $\mathrm{Cr}$ \\
\hline Carbon steel & 0.160 & 0.36 & 1.39 & 0.015 & 0.0032 & 0.006 & 0.008 & 0.017 \\
3\%Ni steel & 0.014 & 0.29 & 0.97 & 0.004 & 0.0029 & 3.00 & $<0.002$ & $<0.002$ \\
5\%Ni steel & 0.015 & 0.30 & 0.98 & 0.005 & 0.0031 & 5.03 & $<0.002$ & $<0.002$ \\
7\%Ni steel & 0.014 & 0.30 & 0.99 & 0.005 & 0.0032 & 7.08 & $<0.002$ & $<0.002$ \\
\hline
\end{tabular}

and in the $2 \theta$ range of $5^{\circ}$ to $100^{\circ}$.

The rust layer near the metal interface of $5 \% \mathrm{Ni}$ steel was analyzed by transmission electron microscopy-energy dispersive spectroscopy (TEM-EDS). Rust specimens $(10 \mu \mathrm{m} \times$ $10 \mu \mathrm{m}$ ) were obtained from the cross section of the steel by focused ion beam (FIB) microsampling using a $10 \mathrm{kV}$ Ga ion beam (Hitachi High-Technologies NB5000 system, Japan). The TEM-EDS measurements were conducted with a JEM2100F field emission electron microscope (JEOL Ltd., Japan), and a $\mathrm{Cu}$ mesh was used to fix the sample. The accelerating voltage was $200 \mathrm{kV}$, and the EDS probe diameter (JED2300T, JEOL Ltd., Japan) was approximately $2 \mathrm{~nm}$.

\subsection{Measurement of Crack Width and Volume in the Rust Layer}

The mercury intrusion method was applied to measure the width and volume of cracks in the rust layers of the carbon steel and the $5 \%$ Ni steel. Specimens with a size of $17 \mathrm{~mm} \times$ $17 \mathrm{~mm} \times 5 \mathrm{~mm}$ were mechanically cut from the exposed samples, and the thickness of rust layer on them was thinned to approximately $100 \mu \mathrm{m}$ using a cutting knife. The cross sections were polished with a grinder to \#400 to prevent burrs that could interfere with the measurement.

The specimen was sealed with mercury in a porosimeter (AutoPore IV 9500, Micrometrics, United States). This method can estimate the pore size distribution in a wide range from several hundred micrometers to several nanometers. The porosimeter measures the volume of mercury intruding into the cracks in the rust layer as the pressure was changed in the range of $0.007-413 \mathrm{MPa}$. The results were analyzed by the software included with the porosimeter. The widths of the cracks were calculated from the volume of intruded mercury at each applied pressure, and used to determine the volume of cracks at each width. ${ }^{14)}$

\subsection{Ion Permeation Resistance of the Rust Layer}

The ion permeation resistance of the rust layer was measured by a rust stability tester (RST, Nippon Steel Anti-Corrosion, Japan). ${ }^{15)}$ Meanwhile, the thickness of the rust layer on the exposed samples was obtained using an ultrasonic thickness gauge and correlated with the ion permeation resistance.

\subsection{Electrochemical Measurements}

Working electrodes were prepared from the exposed carbon steel and 5\% Ni steel plates as follows. A specimen of $10 \mathrm{~mm} \times 20 \mathrm{~mm} \times 5 \mathrm{~mm}$ was mechanically cut from the surface of an exposed piece, leads were soldered to its surface, and the entire surface except for a test area of 50 $\mathrm{mm}^{2}$ was covered with silicone resin. As the rust thickness was different on the two types of steel, it was adjusted approximately $100 \mu \mathrm{m}$ with a cutting knife. The rust thickness after adjustment was measured with an electromagnetic film thickness meter. For comparison, electrodes made of unexposed carbon steel and 5\% Ni steel were also prepared from \#600 polished plates using the same steps as for the exposed specimens.

Argon-deaerated 3\% NaCl aqueous solution at $303 \mathrm{~K}$ was used as the electrolyte. The electrodes were immersed for $15 \mathrm{~min}$ in the electrolyte before measurements. Polarization measurements were performed at a scan rate of $20 \mathrm{mV} / \mathrm{min}$, 
and potentiostatic measurements of rust reduction were also performed in the same electrolyte. A potential of $-600 \mathrm{mV}$ vs. SSE was applied following Doi et al. ${ }^{16)}$ and Sugae et al. ${ }^{17)}$ to selectively reduce $\beta$ - and $\gamma-\mathrm{FeOOH}$ but not $\alpha-\mathrm{FeOOH}$.

\section{Results}

\subsection{Appearance and Corrosion Rate of Exposed Speci- mens}

Figure 1 shows that the appearance of the exposed specimens varied with the Ni content. On the carbon steel, reddish brown and multilayered exfoliated rust was formed. The rust exfoliation was suppressed with increasing Ni content. In contrast, the surface color of Ni-containing steels changed to dark brown, as the fine-grained rust particles absorb light more strongly.

All the specimens were generally corroded, and their corrosion loss was calculated from the weight change after derusting. Figure 2 shows that the corrosion loss after 1 year of exposure decreased sharply as the $\mathrm{Ni}$ content increased. In the subsequent discussion, we only considered carbon steel and $5 \% \mathrm{Ni}$ steel as a representative for the Ni-containing steels.

\subsection{Characterization of Rust on Exposed Specimens}

Figure 3 shows the cross-sectional polarizing micrographs of rust layers on the carbon steel and $5 \% \mathrm{Ni}$ steel. Cracks approximately $2-50 \mu \mathrm{m}$ in width were observed on both types of specimens. However, the average crack width for $5 \% \mathrm{Ni}$ steel was narrower than that for carbon steel, and the number of cracks in the former was also fewer.

Figure 4 shows the EPMA result for the cross sections of the rust layers. The distribution of $\mathrm{Fe}$ and $\mathrm{O}$ was uniform throughout the rust layer and not appreciably affected by the addition of $\mathrm{Ni}$. The rust formed on $5 \% \mathrm{Ni}$ steel also contained $\mathrm{Ni}$ with a uniform distribution throughout. $\mathrm{Cl}$ was detected at the interface between the metal and the rust layer for both types of steel, while its concentration was lower for the $5 \%$ Ni steel.

\subsection{Measured Crack Width and Volume in the Rust Layer}

Quantitative and three-dimensional measurement of the cracks having a wide range of widths and volumes was carried out for the exposed steel specimens using the mercury intrusion method. The results are shown in Fig. 5. The cracks in the rust on carbon steel and 5\% Ni steel had widths between 6 and $100 \mu \mathrm{m}$. These values determined by the mercury intrusion method are generally in good agreement with those measured using optical microscopy on the cross sections (Fig. 3). The volume of mercury intruded into the cracks was lower for the $5 \% \mathrm{Ni}$ steel. For cracks with a width of $\sim 100 \mu \mathrm{m}$, the total volumes of mercury intruded into them were $0.61 \times 10^{-4}$ and $1.44 \times 10^{-4} \mathrm{~mL} /$ $\mathrm{mm}^{3}$ for $5 \% \mathrm{Ni}$ steel and carbon steel, respectively (Fig. 5 ), being approximately $60 \%$ smaller in the former. On the

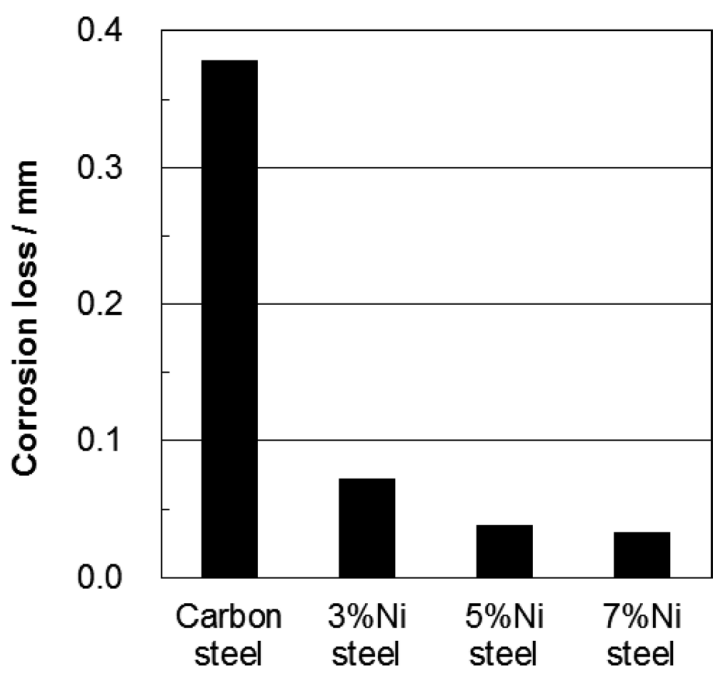

Fig. 2. Corrosion rates of samples after the exposure test.
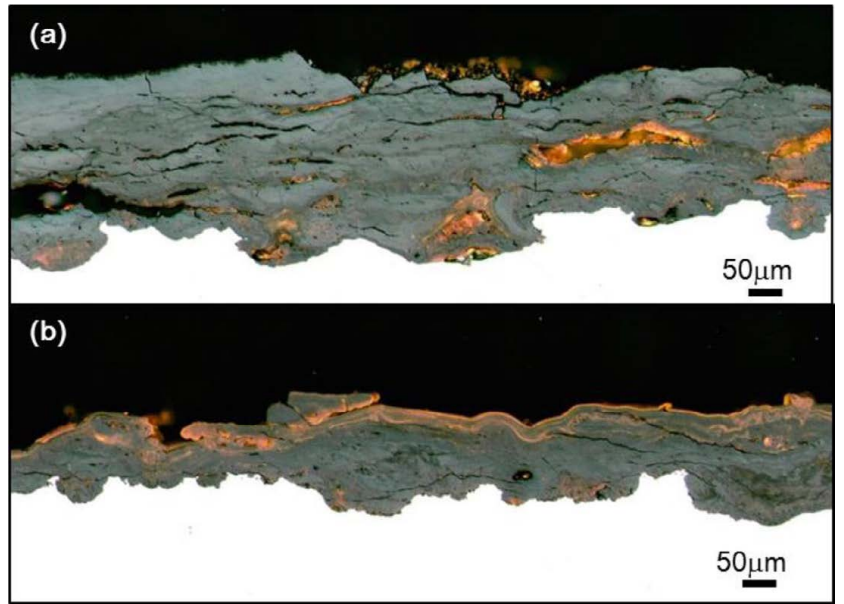

Fig. 3. Polarizing microscopic images of the rust layer formed on (a) carbon steel and (b) $5 \% \mathrm{Ni}$ steel. (Online version in color.)
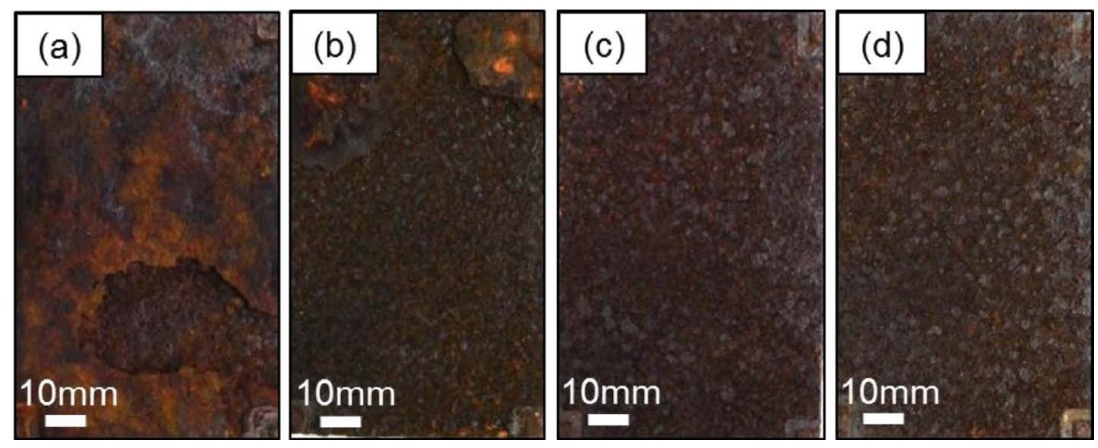

Fig. 1. Appearance of the samples after the exposure test. (Online version in color.) 


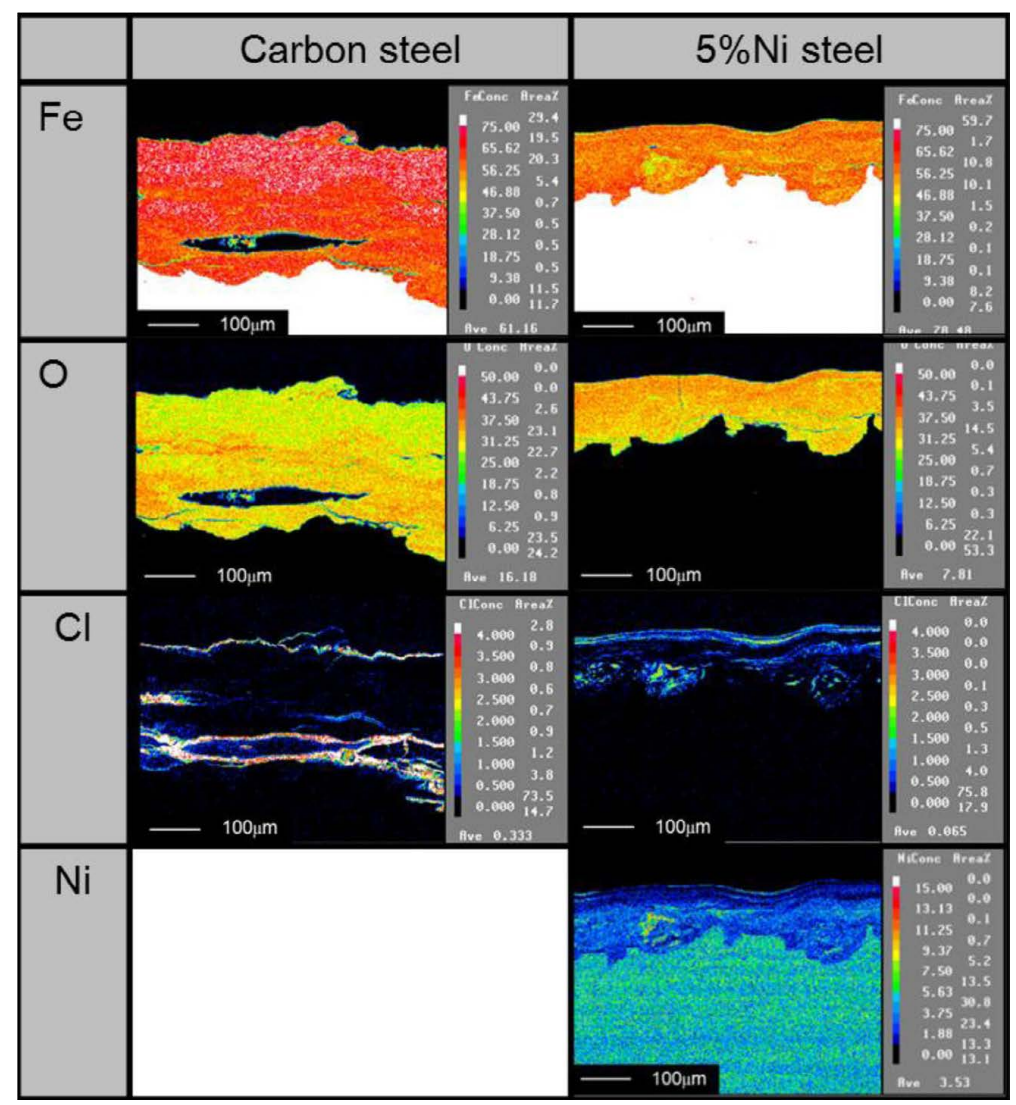

Fig. 4. EPMA measurement results for the rust layers formed on carbon steel and $5 \% \mathrm{Ni}$ steel. (Online version in color.)

(a)

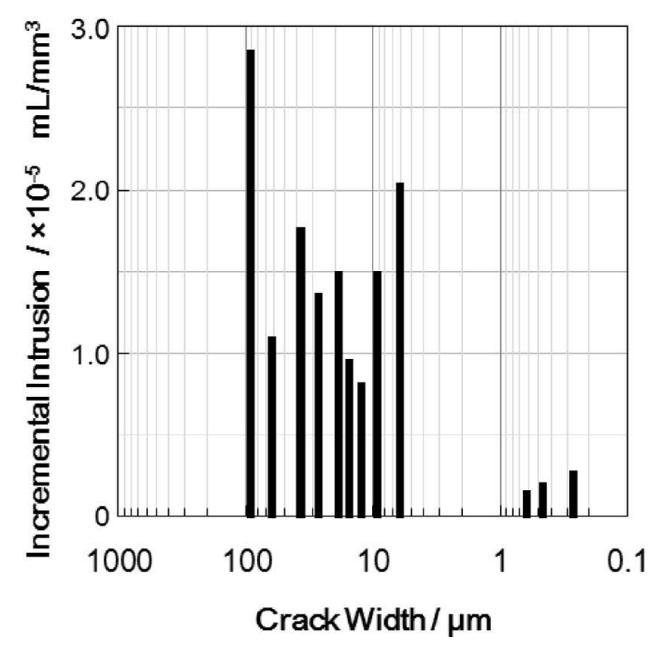

(b)

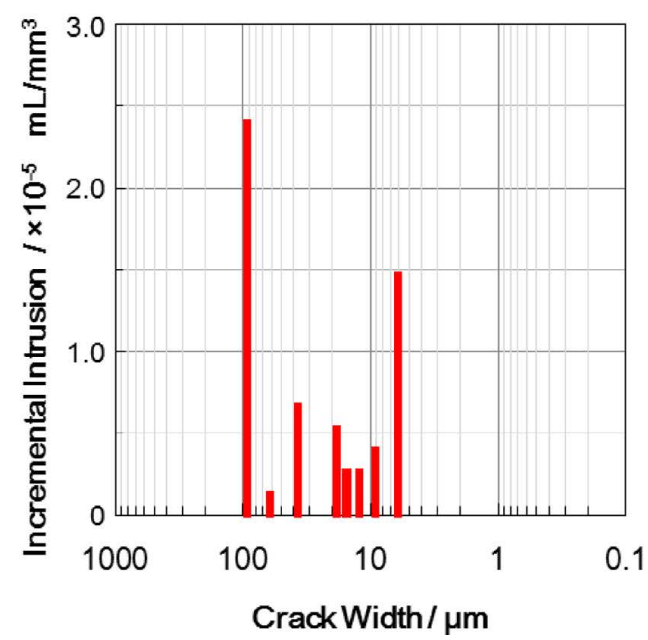

Fig. 5. Results of the mercury intrusion porosimetry tests on carbon steel and $5 \%$ Ni steel. (Online version in color.)

carbon steel, mercury also intruded into voids with a width of $0.26-0.61 \mu \mathrm{m}$. As these voids are too small to be considered cracks, they are likely voids between the rust particles. It is possible that the rust particles were relatively larger in the carbon steel, which facilitates the intrusion of mercury. The above results quantitatively clarify that the volume of cracks in the rust layer was lower in the $5 \% \mathrm{Ni}$ steel than in carbon steel.

In Fig. 6, ion permeation resistances of the rust layer are plotted against the rust thickness. The rust layer formed on carbon steel was thick and showed a low ion permeation resistance, while that formed on the $5 \% \mathrm{Ni}$ steel was thin but had a high ion permeation resistance. These results correlate well with those obtained using the mercury intrusion method.

\subsection{Polarization Measurement of Exposed and Unex- posed Specimens}

Figure 7 shows the polarization curves of carbon steel and 5\% Ni steel. For unexposed specimens and those exposed in Miyakojima for a year (Figs. 7(a) and 7(b)), both exposed specimens showed higher cathodic current densities due to the reduction reaction of rust, with a slightly lower absolute value in the $5 \% \mathrm{Ni}$ steel than in the carbon steel. According to the anodic polarization curves, the exposed 
$5 \% \mathrm{Ni}$ steel exhibited a markedly lower metal dissolution rate than the exposed carbon steel, as shown in Fig. 7(b).

\section{Discussion}

\subsection{Corrosion Resistance Mechanism of Ni-containing Steel in the Subtropical Seashore Environment}

According to previous studies, even the " $3 \% \mathrm{Ni}$ advanced weathering steel" cannot form the protective rust in the subtropical seashore area. Nevertheless, the Ni-containing steel showed less corrosion loss compared with carbon steel (Fig. 2). The reason for this improvement can be explained by suppression of rust exfoliation and crack formation inside rust.

Morchilo reported that cracks in the rust layer lead to rust exfoliation. ${ }^{12)}$ After the exposure test, the carbon steel formed exfoliated rust, while it was suppressed after $\mathrm{Ni}$ addition (Fig. 1). It is suggested that rust layer formed on $5 \% \mathrm{Ni}$ steel contained fewer cracks, and this was directly confirmed by Figs. 3 and 5. Cano and Diaz et al. found that, compared to ordinary WS, Ni-containing steel had better corrosion resistance when exposed in a saline environment.

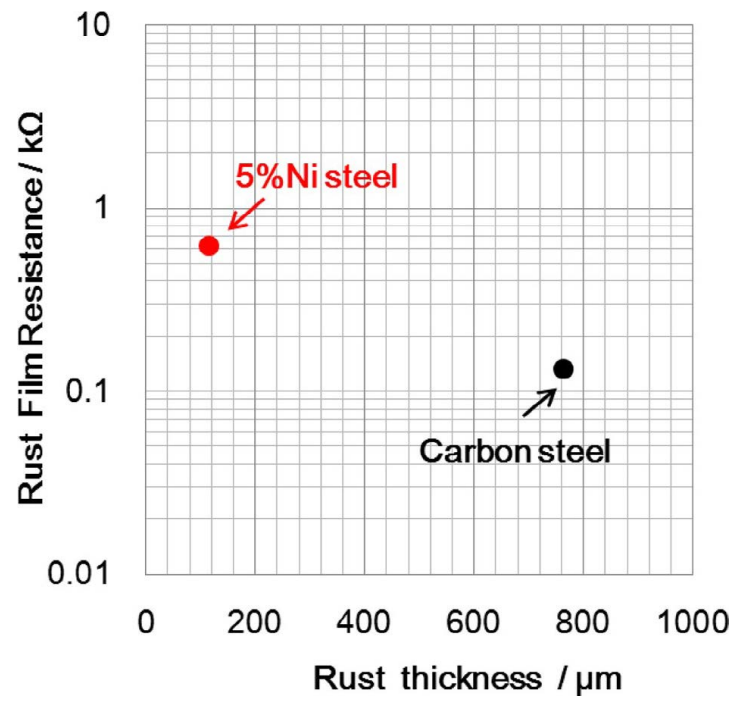

Fig. 6. Thickness and resistance of the rust film formed on carbon steel and 5\% Ni steel after exposure for a year. (Online version in color.)

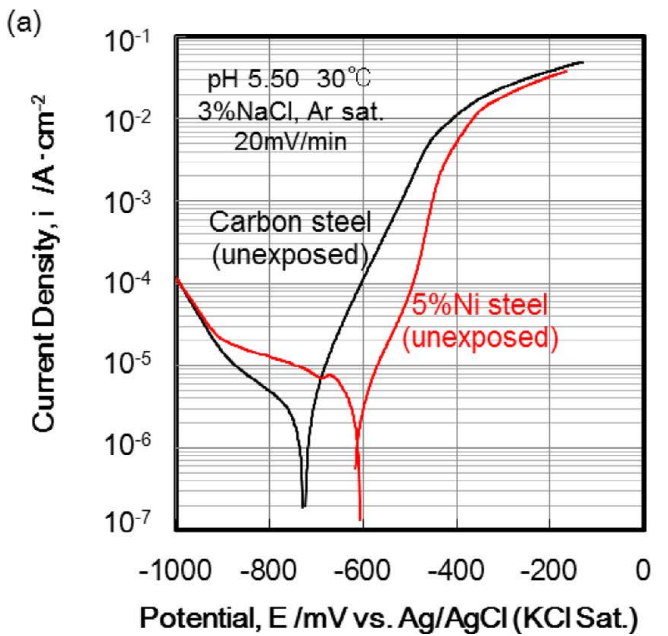

Using cross-sectional microscopy observation, those authors also found fewer cracks in the rust layers on the Ni-containing steel than those on ordinary WS. However, they did not discuss relationship between corrosion resistance and cracks in the rust layer on either sample. ${ }^{18,19)}$

Next, we discuss the relationship between cracks in the rust layer and the corrosion resistance of the steels. $\mathrm{Cl}^{-}$is the most aggressive anion for steel corrosion in the subtropical seashore. It can penetrate rust layers through the cracks to reach the steel interface and accelerate corrosion, as confirmed by our findings in Figs. 4 and 6. First, at the steel/rust interface of $5 \% \mathrm{Ni}$ steel, there was less $\mathrm{Cl}$ compared to that for carbon steel (Fig. 4) due to the fewer cracks. Second, the 5\% Ni steel showed a relatively higher ion permeation resistance despite having a thinner rust layer (Fig. 6). In summary, the enhanced corrosion resistance of Ni-containing steels in the subtropical seashore environment could be attributed to suppressed $\mathrm{Cl}^{-}$migration through the rust layers with fewer cracks.

Finally, we discuss the effect of the rust layer with fewer cracks on the atmospheric corrosion of steel in detail. Atmospheric corrosion of steel proceeds by wet-and-dry cycles, and the corrosion rate is higher in two stages: the early stage of wetting and the drying stage. In both stages, the steel corrosion rate is determined by cathodic reaction. ${ }^{21,22)}$ (1) Just after wetting, the cathodic reaction is the reduction of rust. As shown in Fig. 7, the reduction current of rust is very large for both carbon steel and 5\% Ni steel. On the other hand, the anodic current density of $5 \% \mathrm{Ni}$ steel was much lower owing to the presence of fewer cracks. Hence, in this stage, it is considered that the $5 \% \mathrm{Ni}$ steel hinders corrosion by reducing the anodic dissolution of steel. (2) As the water film dries and becomes thinner, the oxygen reduction reaction increases. Cano et al. considered that oxygen permeability may be suppressed when this layer contains fewer defects. ${ }^{18)}$ In this stage, the corrosion potential of steel becomes noble. For the anodic reaction, the rusted $5 \% \mathrm{Ni}$ steel suppresses the anodic dissolution rate as shown in Fig. 7. Therefore, the more intact rust layer formed on $5 \% \mathrm{Ni}$ steel might decrease the anodic dissolution and hinder corrosion in the drying stage. In future work, we should study the corrosion behavior of rusted steel in wet-and-dry cycles. Stratmann

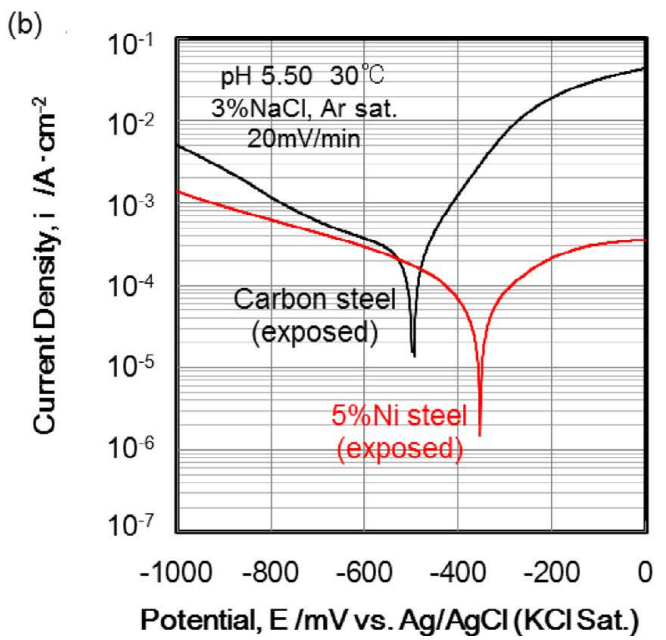

Fig. 7. Polarization curves for carbon steel and $5 \% \mathrm{Ni}$ steel (a) before and (b) after the exposure test in $3 \% \mathrm{NaCl}$ solution at $30^{\circ} \mathrm{C}$. (Online version in color.) 
and Kamimura examined the corrosion behavior of steel in the drying stage. ${ }^{21,23)}$ However, the samples they analyzed were steel and low-alloy steel that form thin rust layers, while details for steels forming a thick rust layer are not fully understood and will require new measurement methods.

\subsection{Mechanism for Suppressed Crack Formation by Added Ni}

Now, we discuss suppression mechanism for crack formation in the rust layer on Ni-containing steels. Morcillo et $a l .{ }^{12)}$ reported that rust exfoliation on carbon steel exposed

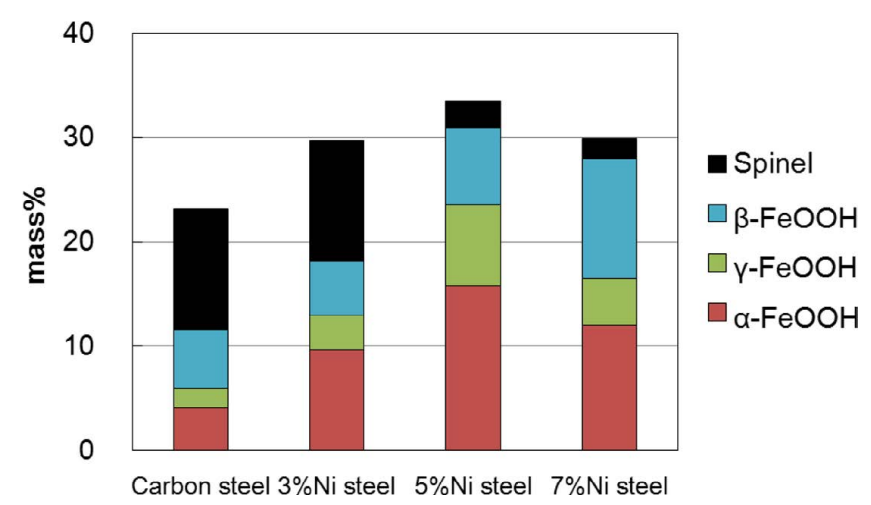

Fig. 8. Mass content of the rust phase determined by X-ray diffraction data. (Online version in color.) in a coastal area may be driven by the volume change when $\gamma$ - and $\beta$-FeOOH transform into $\mathrm{Fe}_{3} \mathrm{O}_{4}$. The unit cell volume per $\mathrm{Fe}$ atom of $\gamma-\beta$-FeOOH, and $\mathrm{Fe}_{3} \mathrm{O}_{4}$ are very different (approximately $2.47,16.9$, and $3.73 \times 10^{-26} \AA^{3}$, respectively). Transformation of $\gamma$ - or $\beta$-FeOOH to $\mathrm{Fe}_{3} \mathrm{O}_{4}$ leads to local volume change of the rust layer. They examined in detail the surface portions of exposed carbon steel with exfoliated rust. The exfoliated rust and residual rust on the

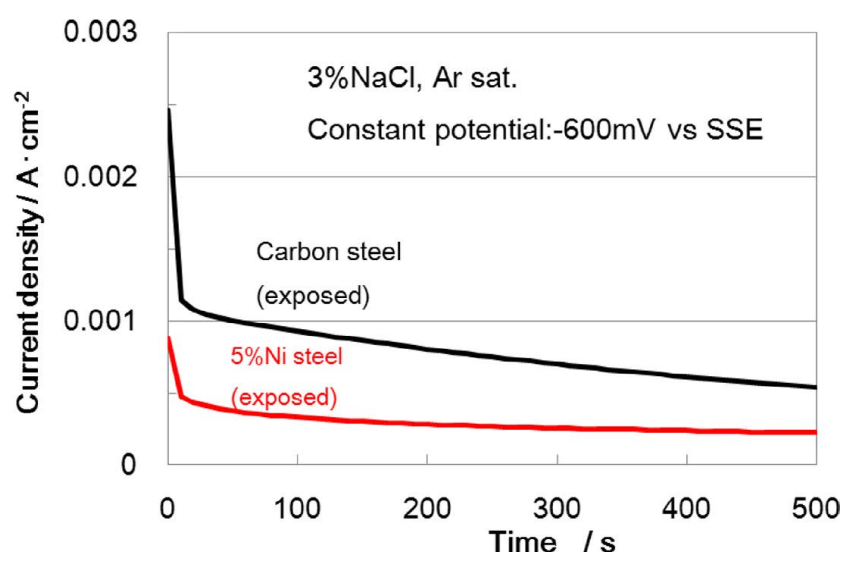

Fig. 9. Cathodic reduction characteristics of rust layers on carbon steel and 5\% Ni steel according to potentiostatic measurements. (Online version in color.)
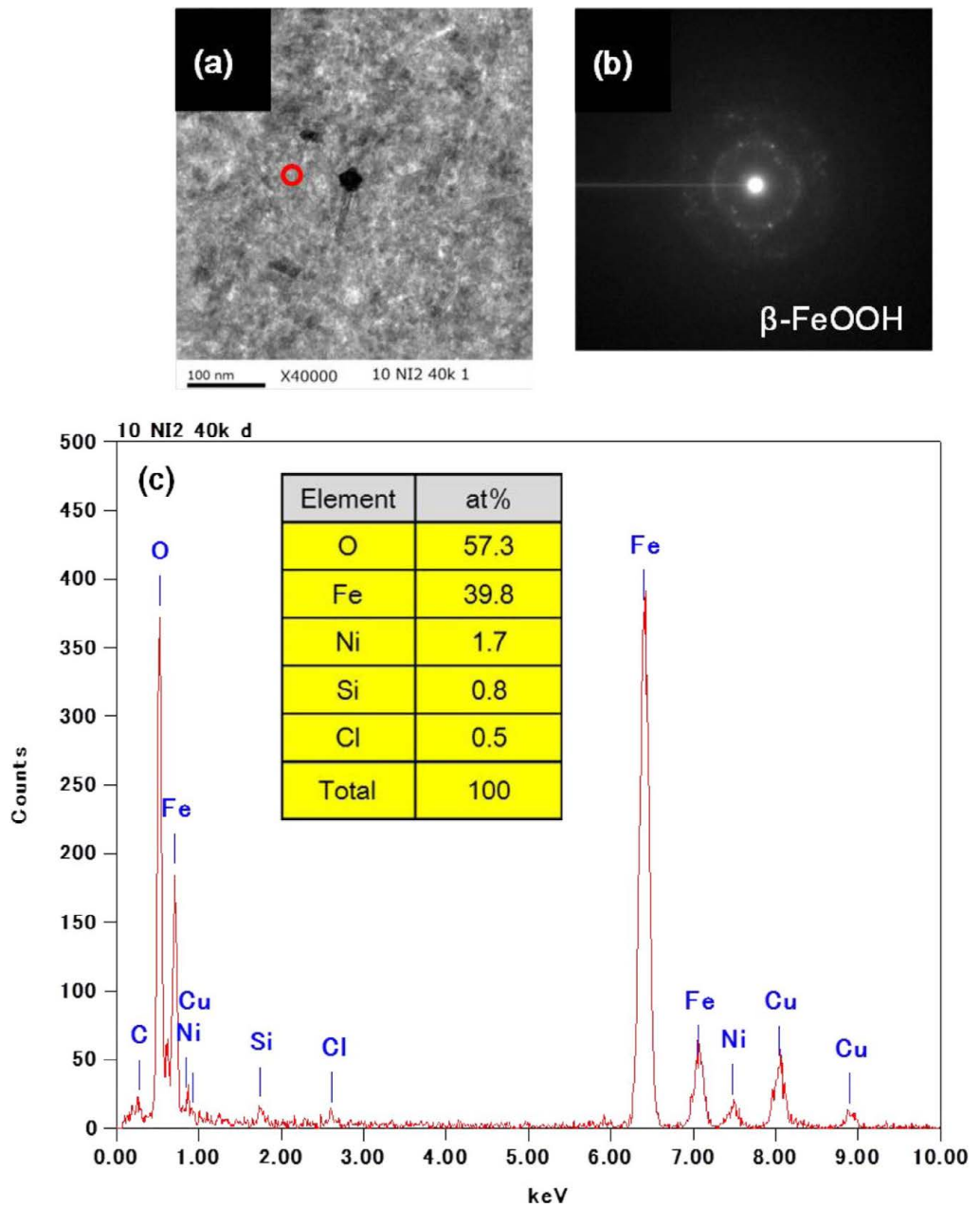

Fig. 10. TEM-EDS analysis result of rust formed on $5 \% \mathrm{Ni}$ steel after exposure for a year: (a) bright field image, (b) diffraction pattern of the area marked by the red circle, and (c) EDS analysis result for the area marked by the red circle. (Online version in color.) 
metal surface contained large amounts of $\gamma, \beta$ - $\mathrm{FeOOH}$, and $\mathrm{Fe}_{3} \mathrm{O}_{4}$, respectively. That report suggests the possibility that phase transformation of the rust occurs in the wet period. The resulting volume change creates voids to facilitate rust exfoliation, starting from the formation of cracks.

In the aforementioned model, there are three possible causes for the suppressed crack formation in the rust layer on the Ni-containing steel: (1) enhanced formation of $\alpha-\mathrm{FeOOH}$, a rust that is known to be hardly reducible; (2) suppressed formation of $\gamma$ - and $\beta-\mathrm{FeOOH}$, which are easily reducible; and (3) suppressed reduction of $\gamma$-and $\beta$ - $\mathrm{FeOOH}$ while their formation is unaffected.

According to the XRD data used to quantitatively identify phases in the rust (Fig. 8), the ratio of $\alpha-\mathrm{FeOOH}$ increased with $\mathrm{Ni}$ addition, in good agreement with possibility (1) above. Meanwhile, (2) is not possible because the ratios of $\gamma$ - and $\beta$-FeOOH also increased with $\mathrm{Ni}$ addition. Tahara reported the same results for $\mathrm{Fe}-\mathrm{Ni}$ alloys exposed in a subtropical seashore environment. ${ }^{24)}$ Increased ratios of $\gamma$ - and $\beta$ - $\mathrm{FeOOH}$ upon $\mathrm{Ni}$ addition indicate a change in their reducibility. In other words, the $\gamma$-and $\beta$-FeOOH were not easily reduced in the corrosion reaction, and so they remained in the rust layer. However, there are few reports about the reducibility of $\gamma$-and $\beta$ - $\mathrm{FeOOH}$ formed on Ni-containing steel. Thus, the reducibility of rust formed on exposed carbon steel and 5\% Ni steel was studied by electrochemical methods, and the results are consistent with possibility (3).

The electrochemical reduction characteristics of rust formed on carbon steel and 5\% Ni steel were examined using potentiostatic measurements at a potential of $-600 \mathrm{mV}$ vs. SSE to selectively reduce $\beta$ - $\mathrm{FeOOH}$ and $\gamma$-FeOOH. ${ }^{16,17)}$ The results are shown in Fig. 9. The electric resistance over $0-500 \mathrm{~s}$ was $0.29 \mathrm{C}$ for carbon steel, while that for $5 \% \mathrm{Ni}$ steel $(0.12 \mathrm{C})$ was approximately $60 \%$ lower. Thus, $\gamma$ - and $\beta$ - $\mathrm{FeOOH}$ in the rust layer on $5 \% \mathrm{Ni}$ steel were indeed less reducible than those formed on carbon steel.

Concerning the structure of $\beta$ - $\mathrm{FeOOH}$ on Ni-containing $\mathrm{Fe}$, Buchwald and Clarke ${ }^{25)}$ analyzed $\beta$ - $\mathrm{FeOOH}$ in meteoric $\mathrm{Fe}$, and estimated its structure as $\left[\mathrm{Fe}_{15} \mathrm{Ni}\right]\left[\mathrm{O}_{12}(\mathrm{OH})_{20}\right] \mathrm{CI}_{2}(\mathrm{OH})$ with some $\mathrm{Fe}$ sites substituted by Ni. It is possible that the coordination of $\mathrm{Ni}$ into $\beta$ - $\mathrm{FeOOH}$ affects its reduction characteristics. In this study, rust formed near the metal interface of 5\% Ni steel was analyzed using TEM-EDS. The results (Fig. 10) indicate that the $\beta$ - $\mathrm{FeOOH}$ contained $1-3 \% \mathrm{Ni}$ in addition to $\mathrm{Fe}, \mathrm{O}$, and $\mathrm{Cl} . \gamma-\mathrm{FeOOH}$ could not be analyzed using this approach, and there is not enough evidence to determine its structure on Ni-containing Fe. However, TEM-EDS analysis of the $5 \% \mathrm{Ni}$ steel showed that the formed $\alpha-\mathrm{FeOOH}$, which could be generated from $\gamma-\mathrm{FeOOH},{ }^{3)}$ also contained Ni. These results suggest the possibility that $\mathrm{Ni}$ affected the chemical property of $\gamma$ - and $\beta$-FeOOH and changed their reducibility. As explained above, the rust layer formed on $5 \% \mathrm{Ni}$ steel contained fewer cracks due to the increased $\alpha$ - $\mathrm{FeOOH}$ formation and suppressed reduction of $\gamma$ - and $\beta$ - $\mathrm{FeOOH}$ in the corrosion process.

\section{Conclusions}

Carbon steel and steels containing 3\%,5\%, and $7 \% \mathrm{Ni}$ were exposed for 1 year in a subtropical coastal area in Miyakojima, where the deposition rate of airborne salt is 1.2 mdd. Various analyses including electrochemical measurements were conducted on the exposed specimens to obtain the following results.

- The addition of Ni improved the corrosion resistance of steels.

- Mercury intrusion porosimeter measurement showed that the total crack volume in the rust layers on $5 \% \mathrm{Ni}$ steel was $60 \%$ lower than that on the carbon steel.

- The $\mathrm{Cl}$ concentration near the metal interface was relatively lower in the $5 \% \mathrm{Ni}$ steel. This rust layer also showed higher resistance to ion permeation than that formed on carbon steel. Furthermore, the exposed 5\% Ni steel had a remarkably lower anodic dissolution rate. These results are attributable to the formation of rust layers with fewer cracks on the $5 \% \mathrm{Ni}$ steel.

- Considering the rust layers with fewer cracks formed on Ni-added steel based on Morcillo's model, the Ni addition seems to have increased the ratio of formed $\alpha-\mathrm{FeOOH}$ and suppressed the reduction of $\gamma$-and $\beta$ - $\mathrm{FeOOH}$, giving the rust layer a more intact structure.

- Due to the fewer cracks contained in the rust layer formed on Ni-containing steels, this layer is more effective in inhibiting the transport of $\mathrm{Cl}$ ions through it and improving the corrosion resistance.

\section{REFERENCES}

1) T. Misawa, K. Asami, K. Hashimoto and S. Shimodaira: Corros. Sci., 14 (1974), 279.

2) T. Misawa, T. Kyuno, W. Suetaka and S. Shimodaira: Corros. Sci., 11 (1971), 35.

3) M. Yamashita, H. Miyuki, Y. Matsuda, H. Nagano and T. Misawa: Corros. Sci., 36 (1994), 283.

4) Public Works Research Institute of the Ministry of Construction, Kozai Club and Japan Bridge Association: Joint Research Report on Application of Weathering Steel to Bridges (XX), Public Works Research Institute, Tsukuba, Japan, (1993) (in Japanese).

5) M. Itou, A. Usami, K. Tanabe, T. Tuzuki, T. Kusunoki and Y. Tomioka: Nippon Steel Tech. Rep., 371 (1999), 78 (in Japanese).

6) H. Kihira and M. Kimura: Corrosion, 67 (2011), 095002-1.

7) M. Ito, A. Usami, H. Kihira, T. Hasegawa, Y. Tomita, G. Shigesato, M. Sugiyama and K. Tanabe: Proc. 46th Japan Conf. on Materials and Environments, Japan Society of Corrosion Engineering, Tokyo, (1999), 279 (in Japanese).

8) M. Kimura, H. Kihira, N. Ohta, M. Hashimoto and T. Senuma: Corros. Sci., 47 (2005), 2499.

9) I. Sugimoto and K. Kita: Q. Rep. RTRI, 51 (2010), 33.

10) H. Kihira, T. Senuma, M. Tanaka, K. Nishioka, Y. Fujii and Y. Sakata: Corros. Sci., 47 (2005), 2377.

11) National Institute for Materials Science: Corrosion Date Sheet, http:// smds.nims.go.jp/corrosion/index en.html, (accessed 2020-04-23).

12) M. Morcillo, B. Chico, D. de la Fuente, J. Alcántara, I. Odnevall Wallinder and C. Leygraf: J. Electrochem. Soc., 164 (2017), C8.

13) T. Kamimura, S. Hara, H. Miyuki, M. Yamashita and H. Uchida: Corros. Sci., 48 (2006), 2799.

14) H. M. Rootare and C. F. Prenzlow: J. Phys. Chem., 71 (1967), 2733.

15) H. Kihira, S. Ito and T. Murata: Corrosion, 45 (1989), 347

16) T. Doi, T. Kamimura and M. Sato: Mater. Trans., 53 (2012), 1536.

17) K. Sugae, T. Kamimura, R. Asakura, T. Doi, H. Miyuki and T. Kudo: Mater. Corros., 70 (2019), 187.

18) H. Cano, D. Neff, M. Morcillo, P. Dillmann, I. Diaz and D. de la Fuente: Corros. Sci., 87 (2014), 438

19) I. Diaz, H. Cano, D. de la Fuente, B. Chico, J. M. Vega and M. Morcillo: Corros. Sci., 76 (2013), 348.

20) H. Kihira, S. Ito, S. Mizoguchi, T. Murata, A. Usami and K. Tanabe: Zairyo-to-Kankyo, 49 (2000), 30 (in Japanese).

21) M. Stratmann, K. Bohnenkamp and T. Ramchandran: Corros. Sci., 27 (1987), 905.

22) M. Stratmamm: Ber. Bunsenges. Phys. Chem. (J. Bunsen Soc. Phys. Chem.), 94 (1990), 626.

23) T. Kamimura and M. Stratmann: Corros. Sci., 43 (2001), 429.

24) A. Tahara: Proc. Weathering Technology Research Achievement Presentation Meeting, Japan Weathering Test Center, Tokyo, (2003), 65 (in Japanese).

25) V. F. Buchwald and R. S. Clarke, Jr.: Am. Mineral., 74 (1989), 656. 